\title{
The impact of dog therapy on nursing students' heart rates and ability to pay attention in class
}

\author{
Odette Griscti $^{\mathrm{a}, *}$, Liberato Camilleri ${ }^{\mathrm{b}}$ \\ ${ }^{a}$ Nursing Department, Office A231H, Cape Breton University, P.O. Box 5300, 1250 Grand Lake Road, Sydney, Nova Scotia B1P 6L2, Canada \\ ${ }^{\mathrm{b}}$ Department of Statistics and Operations Research, Room 509, Maths \& Physics Building, University of Malta Msida Campus, Msida, MSD 2080, \\ Malta
}

\section{A R T I C L E I N F O}

\section{Keywords:}

Animal assisted therapy

Undergraduate students

Stress

Attention

Vigilance

Mind wandering

Emotional support

Learning environment

\begin{abstract}
A B S T R A C T
In this study we explored if the presence of a therapy dog has an impact on students' stress and ability to pay attention in class. The students' heart rates were measured when the dog was present and when he was absent. The students were also asked to fill in a questionnaire. results showed no significant difference in the students' average and maximum heart rates, between the experimental and control group, however the average resting heart rate was lower when the dog was present. The low resting heart rate coupled with written comments from the students indicate that the presence of the dog did reduce stress and had a calming effect on the students.
\end{abstract}

\section{Introduction}

It is well recognised that university students face multiple stressors during their undergraduate training and that these stressors can impair their physical and mental wellbeing (Bayram and Bilgel, 2008: Furr, Westefeld, McConnell, \& Jenkins, 2001: Ribeiron et al., 2018; Taylor, Bramoweth, Grieser, Tatum, \& Roane, 2013). Recently, pedagogical concerns have been raised on how stress can also negatively impact academic performance (Vaez \& Laflamme, 2008). In this study, we explored if introducing a therapy dog into the classroom influences the stress level and attention span of students in attendance as measured by subjective indexes and verbal accounts.

\section{Literature review}

Studies have shown that university students experience high levels of stress and culture shock when they transition from college life to university culture (Dwyer \& Cummings, 2001). University life can present a challenge because of balancing studies with work and life, academic demands and financial constraints (Ryan, Shochet, \& Stallman, 2010). In the health care field, medical and nursing students have been found to face more stress than other disciplines partly due to the demanding nature of clinical practice as well as physical and mental exhaustion associated with the nature of their work and care (Elias, Ping, \& Abdullah, 2011; Garg, Agarwal, \& Dalal, 2017).

The effect of stress and failure to cope with these stressors can have negative consequences on students' health and academic performance. Stress in undergraduate students have been linked to negative effects on physical and mental well-being such as lack of

\footnotetext{
* Corresponding author.

E-mail addresses: odette_griscti@cbu.ca (O. Griscti), liberato.camilleri@um.edu.mt (L. Camilleri).
} 
sleep (Pagnin \& DeQueiroz, 2015; Taylor et al., 2013), fatigue and burnout (Domantay, 2014; Pagnin \& DeQueiroz, 2015; West, Shanafelt, \& Kolars, 2011) anxiety and depression (Bayram \& Bilgel, 2008; Domantay, 2014), and in extreme cases contemplation of suicide (Furr et al., 2001). In a report on mental health that surveyed 30,000 students in Canada's colleges and universities (American College Health Association, 2016) it was revealed that as much as $90 \%$ of Canadian students felt overwhelmed by all the work they had to do, $63 \%$ felt lonely, $9.5 \%$ considered suicide, while $1.5 \%$ attempted suicide.

The relationship between stress and academic achievement in university students was also described in various studies. Dwyer and Cummings (2001) reported that stress was the most common factor that impacted academic performance in undergraduate students. Similar findings were reported in two separate studies by Elias et al. (2011) and Safree, Yasin, and Dzulkifli (2010) who reported a significant negative correlation between undergraduate students' stress level and their academic achievement. In both studies it was found that the more stressed students were, the lower was their academic achievement.

All these studies suggest that reducing stress in undergraduate students is not only timely, but also imperative. Recently there has been a growing interest in the use of Animal-Assisted Therapy (AAT) as an approach to alleviate stress in university students (Adamle, Riley, \& Carlson, 2009). Studies on human-animal interactions have shown that AAT has a positive effect on well-being by decreasing the level of stress hormones like cortisone (Kertes et al., 2017) and stimulating the release of neurotransmitters like dopamine, oxytocin and endorphins which promote calmness, relaxation and overall well-being (Nagasawa et al., 2015; Odendaal \& Meintjes 2003; Pugliese, Famulari, \& Britti, 2010). In university settings, studies on undergraduate students have shown how pet therapy was effective in bringing about physiological, psychological and pedagogical changes that benefited students. A study by Wood, Ohlsen, Thompson, Hulin, and Knowles (2018) revealed that a 15-minute exposure to a dog significantly reduced blood pressure and selfperceived stress levels in undergraduate students prior exams. These results support findings from an earlier study by Barker, Barker, McCain, and Schubert (2016) who also explored the impact of AAT on college students a week prior to their exams. These researchers used different physiological and psychometric measures than the ones used by Wood et al. (2018), yet also found that interaction between college students and a therapy dog decreased the students' stress level during exam times. Other studies show that AAT helped first-year university students to adjust and fill the absence of social support when they moved to university campus or that helped to promote recruitment and retention of students in universities (Huss, 2012).

Building on these findings, we hypothesize that students who are exposed to the presence of a dog in class would exhibit less stress and pay more attention during class time when a dog was present in comparison when the dog was absent. For this study, stress is defined as "a state of mental or emotional strain or tension resulting from adverse or demanding circumstances" (Oxford dictionary, 2019) while attention is defined as "the behavioural and cognitive process of selectively concentrating on a discrete aspect of information, whether deemed subjective or objective, while ignoring other perceivable information" (Anderson, 2004:519).

\section{Methodology}

The purpose of this exploratory trial was to find out if the introduction of a therapy dog into the classroom affected on the stress level of students in attendance and if it had an impact on students' ability to pay attention in class. The objectives of this study were: 1. To compare if there are physiological changes in students' average, maximum and resting heart rate when the dog was present or absent. 2. To explore if the presence of a dog during class time had an impact on the students' level of attention in class.

The study was conducted in two phases. Phase 1 consisted of a randomized, controlled, within-subject exploratory trial. Subjective indexes were used to measure the student's heart rate (HR) when the dog was present and when he was absent. Phase 2 involved the collection of subjective accounts from students using a semi structured questionnaire. Permission to bring a pet in class was sought from the Research Ethics Board (REB) at the university where the study took place and from the students. No special permission was required from the university to get the dog in class, however since there was a potential risk that the dog may harm the students, the REB required the researcher to certify that the dog in question was given all necessary vaccinations and that his temperament was calm and obedient. Another potential risk was that some students could be allergic or afraid of dogs. To safeguard against this, prior to the commencement of the study, the students were asked to write yes/no answer on an anonymous piece of paper, if they agree to have the dog in class or not. Emphasis was made to the students to submit a "no" answer if they are allergic or afraid of dogs, or if of any other reason, they preferred not to have the dog in class. All the students consented. The dog was brought to class the following week on designated days of the course. He was left to roam around the class while the lecture was going on. For most of the time the dog would visit the students, who smiled and petted him. At other times he would lie on his blanket at the front of the room and watch what was going on or have a nap

Data were collected over an 8-week period from January 2017 until March 2017. The students selected for this study were currently enrolled in a specific nursing course at a Canadian university in Nova Scotia. These students were in their second year of the programme and were currently being taught by this course by one of the researchers.

\section{Measures}

\subsection{Physiological measurements}

An optical wrist HR monitor was used to measure the students' HR when the dog was present or absent in class. The wrist HR monitor was designed to monitor a user's HR continuously for the whole period that the students were in class. The device was able to capture any fluctuations in HR during this period. The students were asked the wear the watch during class time for the whole duration of the class. In total students were monitored on eight sessions: four sessions when the dog was present and four sessions 
when the dog was absent. Each classroom session was $2.5 \mathrm{~h}$ long. Readings from the students' HR monitor was obtained at the beginning, middle and end of class time. Besides these values, three other subjective indexes were used to measure the students HR in class: average HR, maximum HR and resting HR. These indexes were automatically generated by the optical wrist HR monitor.

A randomized method was used to randomly select 24 nursing students from a class of 38 students enrolled in a nursing course in a University (cluster). The total number of nursing students in the programme was 312 . This yielded a total of 576 observations and guaranteed a maximum margin of error of $4.08 \%$ assuming a $95 \%$ confidence level.

\subsection{Psychological variables}

To evaluate if the presence of the dog had an influence on the students' learning, a semi-structured questionnaire was distributed to all students on the last day of class $(n=38)$. The purpose of this tool was to gain insight and to identify if the presence of the dog during classroom sessions had an impact on the students' ability to pay attention. This questionnaire consisted of open-ended questions seeking information about the students' attitude towards the dog's presence in class, and if the presence of the dog in the class had an impact on their attention span in class.

\section{Data analysis and results}

\subsection{Physiological subjective indexes}

A total of 24 students participated in the study. This consisted of 21 females and 3 males and their ages ranged from 20 to 31 years $(M=22.2$ years, $S D=3.08)$. The statistical package for social science software (SPSS version 24$)$ was used to analyse the data.

\subsubsection{Trends in average HRs of students for each classroom session}

Fig. 1 illustrates the trajectory of the average student HR at the beginning, midway and end of lecture in each of the eight sessions. The trends were similar for each session, where the HR was at its lowest value at the beginning of the lecture, peaked halfway through the lecture, and returned close to baseline at the end of the lecture.

Moreover, the error bar graph (Fig. 2) displays the $95 \%$ confidence intervals of the mean HRs at Times 1, 2 and 3 for all 8 sessions combined. The mean HR at Time 2 was significantly higher than Times 1 and 3 because the $95 \%$ confidence intervals did not overlap.

Using the Shapiro Wilk test, it was found that the HR distributions were skewed and did not satisfy the normality assumption. So, the Friedman test (non-parametric) was used to compare the mean pulse rates between these three time slots. Moreover, post-hoc tests were used for pairwise comparisons between these mean pulse rates and this was carried out both in the presence and absence of the dog.

Table 1 shows that when the dog was present, the mean HR at Time 2 (99.1 beats per minute) was significantly higher than the mean HRs at Time 1 (74.88 beats per minute) and Time 3 (79.43 beats per minute). However, the difference between the latter two

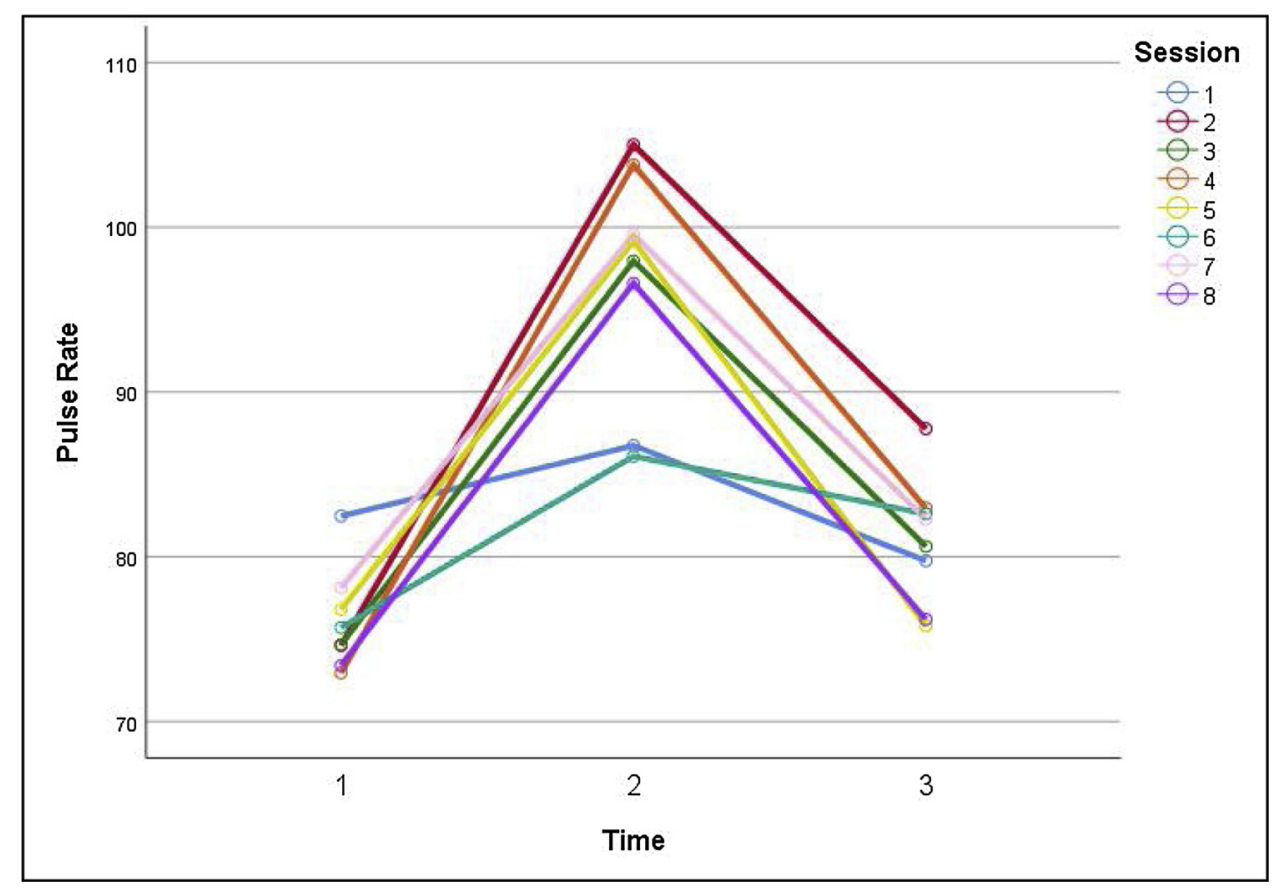

Fig. 1. Mean student HRs, clustered by time of lecture and session. 


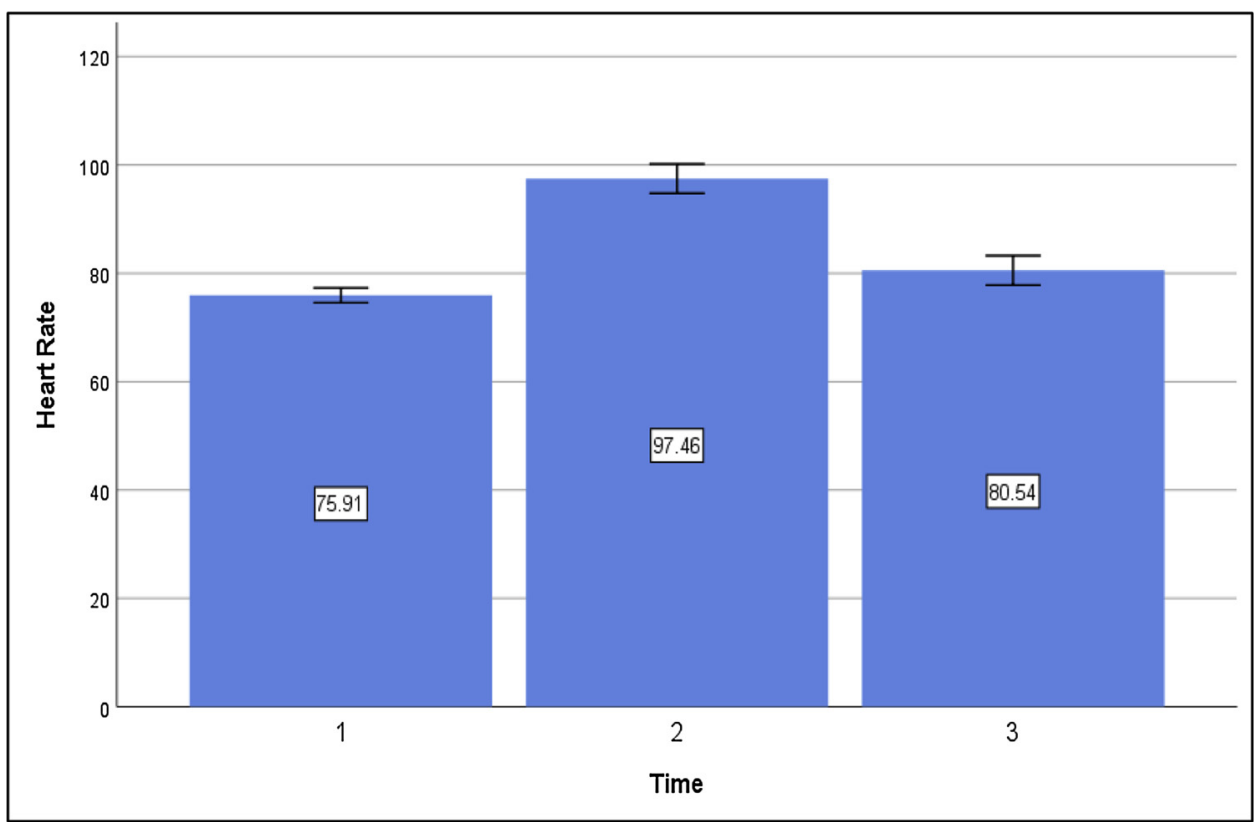

Fig. 2. Mean HRs at Times 1, 2 and 3 for all 8 sessions combined.

Table 1

Mean HRs clustered by time of lecture and presence/absence of the dog.

\begin{tabular}{lllllll}
\hline & Time & Mean HR & Std. Deviation & Lower Bound & Upper Bound & P-value \\
\hline Dog was Present & 1 & 74.88 & 7.520 & 73.18 & 95.35 & 76.59 \\
& 2 & 99.10 & 16.526 & 75.16 & 102.85 & 0.000 \\
Dog was Absent & 3 & 79.43 & 18.795 & 74.19 & 79.42 & 99.42 \\
& 1 & 77.19 & 8.755 & 91.47 & 85.02 \\
\hline
\end{tabular}

HRs was not significant since the p-value (0.150) exceeded the 0.05 level of significance (Table 2).

When the dog was absent, the mean HR at Time 2 (95.44 beats per minute) was significantly higher than the mean HRs at Time 1 (77.19 beats per minute) and Time 3 ( 81.89 beats per minute). However, the difference between the latter two HRs was not significant since the p-value (0.099) exceeds the 0.05 level of significance (Table 3 ).

The error bar graph (Fig. 3) displaying the $95 \%$ confidence intervals of the mean HRs at Times 1, 2 and 3, for the 4 sessions when the dog was present, and the 4 sessions when the dog was absent, complements the results of the post hoc tests. In both cases, the mean HR at Time 2 was significantly higher than Times 1 and 3 because the $95 \%$ confidence intervals do not overlap.

\subsubsection{Students' HR averages}

Three averages were measured to find out the overall impact of the presence of the dog during class times: Average HR, resting HR and maximum HR. A definition of these terms is provided in Table 4.

The Shapiro Wilk test was used to determine whether the average/maximum/resting HR distribution is normal or skewed. For this test, P-values exceeding the 0.05 level of significance indicate that the HR distribution is normal, while p-values less than the 0.05 criterion indicate that the HR distribution is skewed (not normal). Table 5 shows the results of this calculation.

The Shapiro Wilk p-values showed that the resting and average HR distributions were not normal; both when the dog was present and when he was absent. The histograms clearly display that the HR distributions are left skewed and violate the normality

Table 2

Post Hoc Test (Dog was present).

\begin{tabular}{lllll}
\hline Time & Time & Mean HR change & Std. Error & Cohen's d \\
\hline 2 & 1 & 24.22 & 2.432 & 0.000 \\
2 & 3 & 19.67 & 2.432 & 0.000 \\
3 & 1 & 4.55 & 2.432 & 0.974 \\
\hline
\end{tabular}


Table 3

Post Hoc Test (Dog was absent).

\begin{tabular}{llllll}
\hline Time & Time & Mean HR change & Std. Error & P-value & \\
\hline 2 & 1 & 18.251 & 2.266 & 0.000 \\
2 & 3 & 13.556 & 2.257 & 0.000 \\
3 & 1 & 4.695 & 2.266 & 0.769 & 0.099 \\
\hline
\end{tabular}

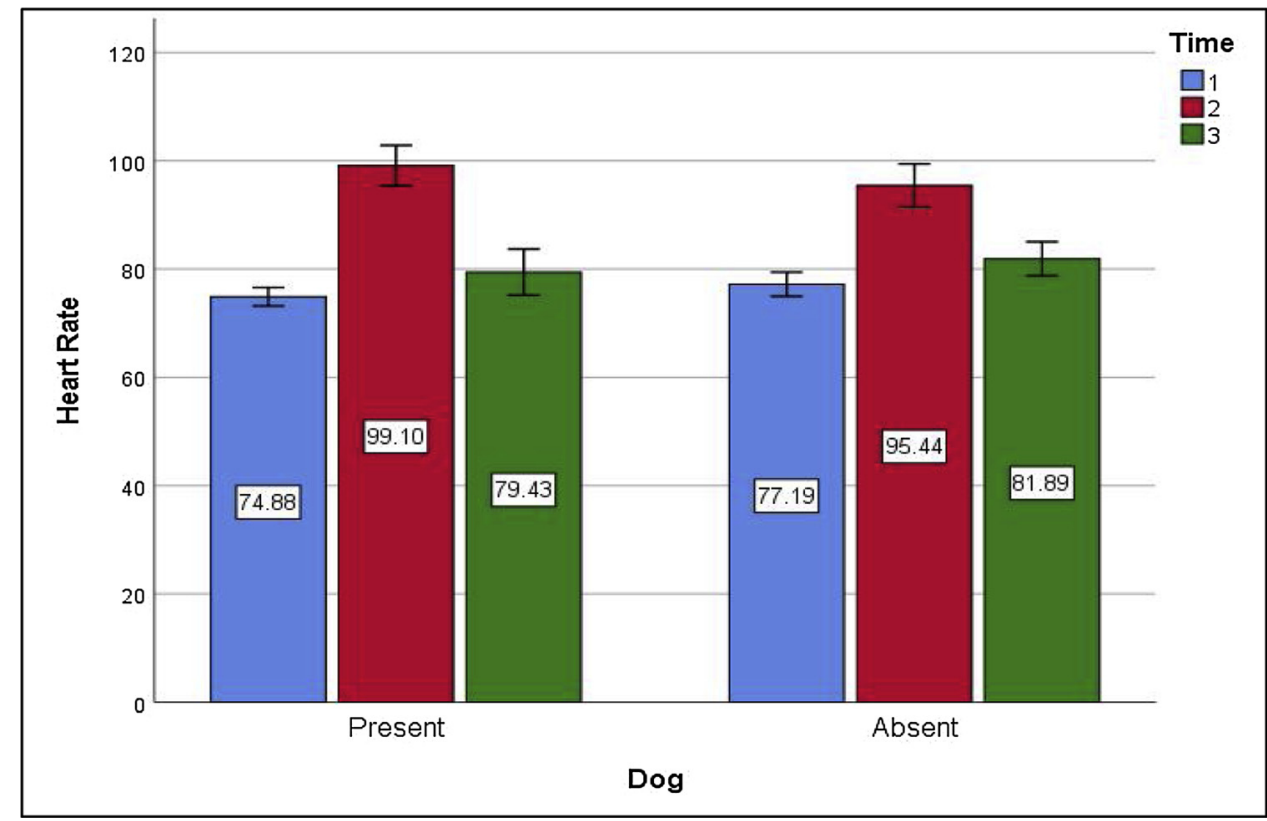

Fig. 3. Mean HRs at Times 1,2 and 3 clustered by presence/absence of the dog.

Table 4

Definition of terms.

\begin{tabular}{ll}
\hline Terminology & Definition \\
\hline Average HR & The average number of heart beats for the whole period of class \\
Resting HR & The number of heartbeats when the heart is completely at rest \\
Maximum HR & The number of heart beats per minute when the heart was working at its maximum \\
\hline
\end{tabular}

Table 5

Shapiro- Wilk Tests of Normality.

\begin{tabular}{lllll}
\hline & & Statistic & df & P-value \\
\hline Average HR & Dog is present & 0.937 & 69 & 0.002 \\
& Dog is absent & 0.941 & 61 & 0.006 \\
Resting HR & Dog is present & 0.952 & 69 & 0.010 \\
& Dog is absent & 0.905 & 61 & 0.000 \\
Maximum HR & Dog is present & 0.980 & 69 & 61 \\
& Dog is absent & 0.981 & 0.335 \\
\hline
\end{tabular}

assumption (Figs. 4 and 5).

On the other hand, the Shapiro Wilk p-values showed that the maximum HR distributions were normal; both in the presence and absence of the dog. Both histograms showed that the HR distributions follow closely the normal curve (Fig. 6) and for this reason both parametric and non-parametric tests will be used to compare mean HRs between the two groups.

The Independent samples $t$-test (parametric test used when the normality assumption is satisfied) and the Mann Whitney test (non-parametric test used when the normality assumption is violated) were used to compare mean HRs between two independent groups (dog was present, the dog was absent). For both tests, a p-value exceeding the 0.05 level of significance indicates no significant difference in the mean HR between the two groups, while a p-value less than the 0.05 criterion indicates a significant difference. 


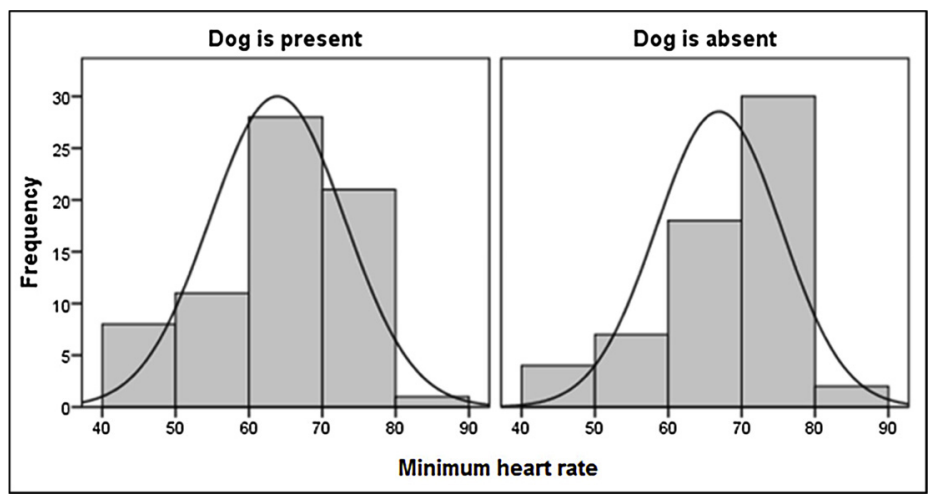

Fig. 4. Minimum HR distributions in the presence/absence of the dog.

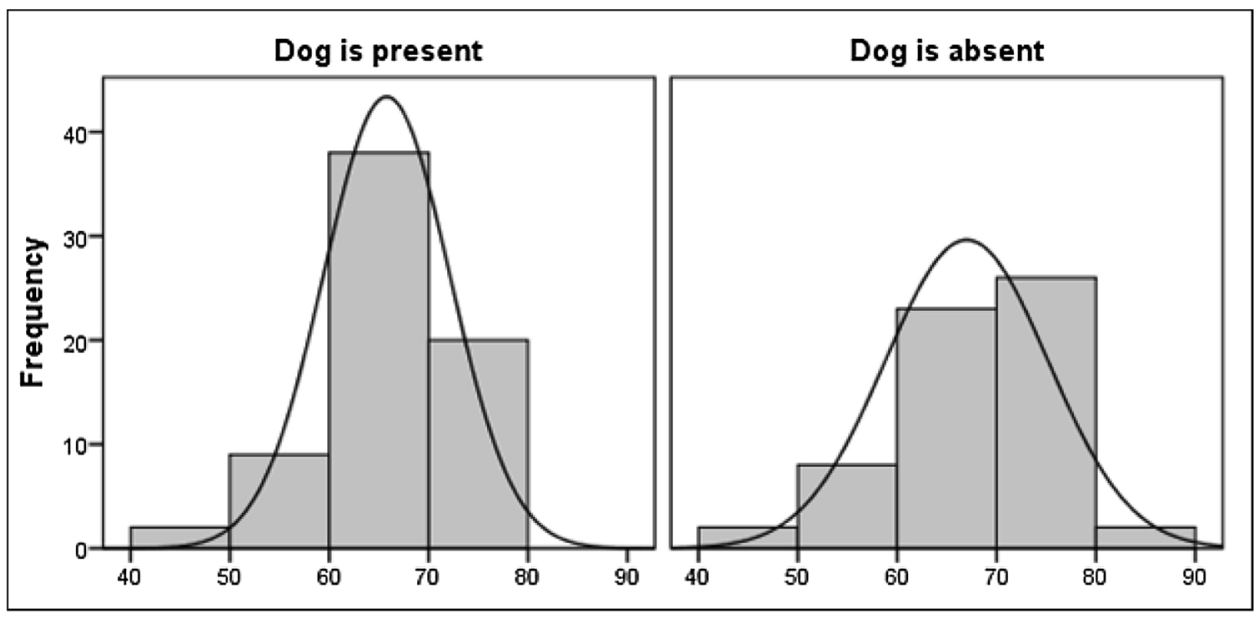

Average Heart Rate

Fig. 5. Average HR distributions in the presence/absence of the dog.

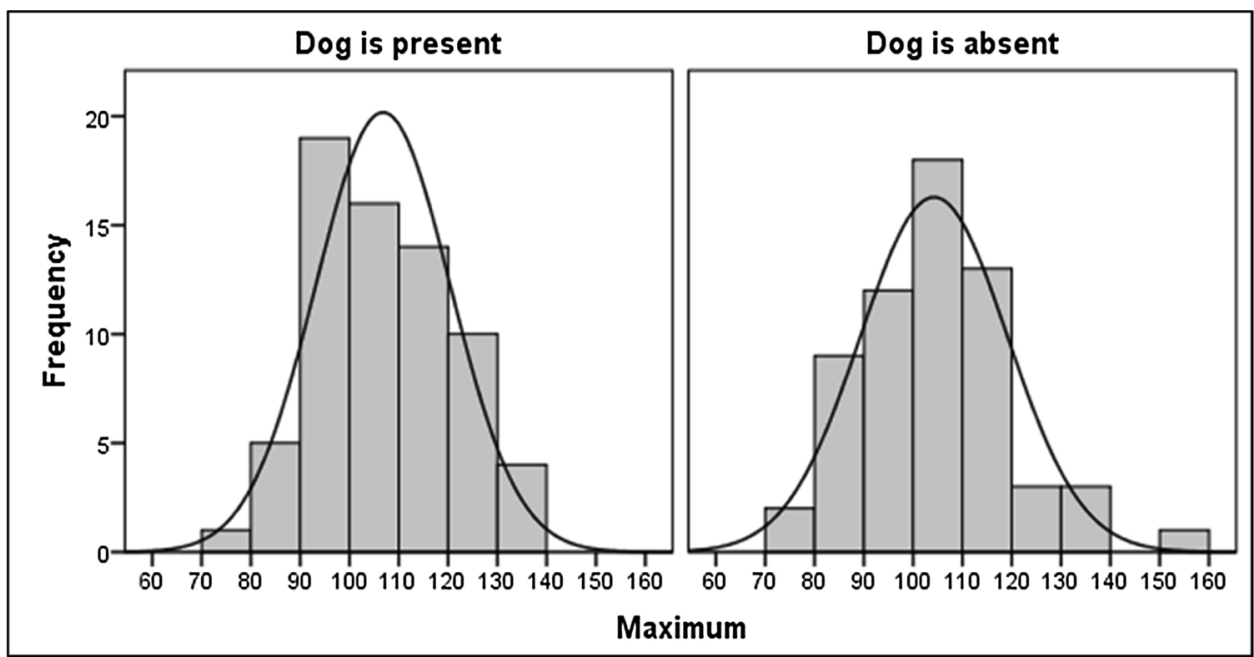

Fig. 6. Shapiro Wilk test result for maximum HR.

Table 6 shows the results obtained from this analysis.

The mean resting HR for the group where the dog was present was significantly lower than the mean resting HR for the group when the dog was absent because the p-value (0.040) was less than the 0.05 level of significance. However, there was no significant 
Table 6

Comparing mean HRs between two groups.

\begin{tabular}{|c|c|c|c|c|c|c|c|}
\hline & Dog is: & Mean HR & Std. Deviation & Lower Bound & Upper Bound & P-value & Cohen's d \\
\hline \multirow[t]{2}{*}{ Average HR } & present & 65.77 & 6.343 & 64.24 & 67.29 & 0.174 & 0.165 \\
\hline & absent & 66.98 & 8.213 & 64.88 & 69.09 & & \\
\hline \multirow[t]{2}{*}{ Resting HR } & present & 63.87 & 9.175 & 61.67 & 66.07 & 0.040 & 0.341 \\
\hline & absent & 66.89 & 8.529 & 64.88 & 68.91 & & \\
\hline \multirow[t]{2}{*}{ Maximum HR } & present & 106.80 & 13.642 & 103.52 & 110.07 & 0.305 & 0.181 \\
\hline & absent & 104.21 & 14.943 & 100.34 & 108.08 & & \\
\hline
\end{tabular}

difference in the mean maximum and average HRs between the two groups because the p-values (0.305 and 0.174$)$ exceeded the 0.05 level of significance. So it can be generalized that the resting HR tended to be lower when the dog was present, however, this result cannot be generalized for the average and maximum HRs.

\subsection{Subjective accounts}

To elicit further information from the students themselves and find out what was happening during each classroom session, the students present on the last day of the class $(n=38)$ were asked to complete a questionnaire. The questionnaire consisted of semi structured questions which allowed the students to share their feelings about having a dog in class and if the presence of the dog had an impact on their ability to pay attention during the lecture. Data from the questionnaires were analysed manually and the semistructured format facilitated the data reduction process. The comments provided by the participants were grouped into themes and their frequency was recorded. Table 7 shows all the themes and corresponding frequencies that were elicited from the students' responses.

Following this stage, similar themes were clustered together into categories. Two main categories emerged from this study. These were: jovial atmosphere, and a positive distraction.

\subsubsection{Jovial atmosphere}

The title of this category was chosen because it captures the buoyant atmosphere that was created in the class, by the presence of the dog. Analysis of the qualitative part of the study consistently indicated that the students enjoyed having the dog in class ( $\mathrm{n}=36$ ). There were no negative remarks about the presence of the dog from any of the students. On the contrary many wrote positive comments about having the dog in class, such as "I wish we had the dogs in more classes" (\#S.7) and "I was disappointed when the dog was not there". (\#S.12). Overall the presence of the dog created a jovial atmosphere in class with some students remarking that they looked "forward to come to class" $(n=3)$ and they were "excited to come to class because of the dog" $(n=2)$ because "class was fun" ( $n=8)$, the dog "changed my bad mood" $(n=2)$, "made me feel happy" $(n=21)$.

\subsubsection{A positive distraction}

When students were asked about the impact of the dog on their ability to pay attention in class, a small number of students $(n=4)$ said the presence of the dog had no impact on them and they were able to pay the same amount of attention in class whether the dog was there. For instance, one student wrote "Did it make a difference when Patches was here? Neutral. I paid the same amount of attention when Patches was here or not, maybe a little happier when he was here" (\#S4). Three students (n = 3) specifically wrote that having the dog in class helped them to "focus more" on the lecture because "the dog created a calm and relaxed atmosphere" (\# S2), "reduced stress in class" (\#32) or created "a comfortable classroom environment" (\# S14). However, most of the students felt

Table 7

Analysis of qualitative data.

\begin{tabular}{ll}
\hline Codes generated & Frequency (n= 38) \\
\hline "enjoyed having the dog in class" & 36 \\
"had no impact on my attention in class" & 3 \\
"distracted me" (no further details) & 3 \\
"distracted me, missed taking down points from the lecture" & 2 \\
"positive distraction" & 19 \\
"relieved my stress" & 18 \\
"made me feel happy" & 21 \\
"made me look forward to coming to class" & 3 \\
"it was exciting to come to class because of the dog" & 2 \\
"class was fun because of the dog" & 8 \\
"changed my bad mood" & 2 \\
"calmed me" & 19 \\
"all classes should have dogs" & 3 \\
"helped me to focus more" & 3
\end{tabular}


that the dog made their minds wander off from the lecture. Two students $(n=2)$ mentioned that when they petted him, they got distracted and they missed jotting down notes related to the lecture. Interestingly, although most of the students commented that having the dog in class was a distraction or made their minds wander, they were quick to point that it was a "positive distractive" ( $n=19$ ). The reason that these students provided to explain why the presence of the dog was a "positive distraction" was similar to the rationale that was given by the three other students who stated that the presence of the dog helped them to focus more in class. These 19 students mentioned that the presence of the dog was a "positive distraction" because looking or interacting with the dog in class helped to calm them and to relieve their stress. For example one student wrote "at times it was distractive, but it was a positive distraction - it was calming more than anything"(\# S.16), another one mentioned that "if I felt stressed just looking at the dog would make me happy and calm" (\#S.14), while another wrote "it was a distraction but not a bad distraction, a nice stress break from constant work" (\# 23). Almost all the students at some point in their questionnaire mentioned that the presence of the dog made them happy $(n=21)$ relieved their stress $(n=18)$ and/or calmed them $(n=19)$, thereby highlighting the positive impact of AAT on the students' mental states.

\section{Discussion of findings}

The purpose of this study was to explore the physiological impact of pet therapy on students and its effect on stress levels and ability to pay attention during class time.

Results show that the HR of the students followed a certain pattern for each class. The HR was within the normal range at the beginning and at the end of class, yet it peaked and was significantly higher midway through the lecture (Fig. 1). This pattern is consistent with the physiological changes that one expects to see in HR when a person is engaged in cognitive activity. It is well documented that learning processes such as increased attention, results in an increased HR (Thayer \& Lane, 2000; Wang, Pinol, Byrne, \& Mendelowitz, 2014). According to the neurophysiology science of vigilance, when one is deeply focused on a task, an impulse is sent from the brain to the vagus nerve in the brain stem. This impulse directly inhibits the parasympathetic system (the nervous system which lowers the HR) and stimulates the sympathetic system (the nervous system which stimulates the heart) which takes over and automatically increases the HR (Thayer \& Lane, 2000; Wang et al., 2014). This pathway is a two-way system, and just as the brain may influence the HR and increase in HR will increase vigilance and alertness (Park \& Thayer, 2014).

Vigilance, or sustained attention, is one's ability to focus on a task for a specific time (Okena, Salinskya, \& Elsasa, 2006). However, attending to unchanging task for a long period of time can lead to vigilance decrement or a decline in vigilance. According to Beatty (1989) exposure to an unchanging stimulus, brings the demise of vigilance, and requires a break from the monotony of the task at hand, if attention is to be successfully maintained. Beatty (1989) adds on that if this stimulus is not there, vigilance cannot be maintained, and the mind will wander off. One can see this pattern clearly from these students' HR trends during class time. There was an increase in the HR as the class progressed and the students' curiosity and attention were aroused, and a decrease in HR as their attention declined over time. This HR pattern was similar between both groups, when the dog was there and when he was absent and there was no statistical difference between groups. Likewise, there was no significant difference in the average HR and the maximum HR of the students with and without the dog present. Based on these physiological findings and the neurophysiology science of vigilance, one can conclude that the students' attention span during class time was not affected by the presence of the dog. It is interesting to note however, that midway through the class, the students HR was higher (non-significant) when the dog was present than when he was absent. This suggests that even though the presence of the dog left no impact on the students, the students were slightly more aroused when the dog was there, at least midway through the class.

The fact that physiologically the dog left little if any impact on the attention of the students, was a surprising result particularly since most of the students admitted that the presence of the dog was a distraction in class that shifted their attention from the lecture. Unlike vigilance, mind wandering is an attendant cognitive function that results when a person is no longer being attentive to the task at hand. However, although mind wandering has been repeatedly described as a divergent mental state that has an opposite effect on cognitive processes (Vago \& Zeidan, 2016), recent research in this field is showing that the extent to which mind wandering impact cognitive performance depends on the stimulus that evokes mind wandering. If the stimulus for mind wandering is pleasant and relaxing, it may reduce stress and improve concentration and cognitive task performance (Banks, McCoy, \& Trzcinski, 2018).

Although the purpose of this was not to measure the impact of AAT on cognitive function of the students, findings from this study indicate that the presence of the dog in class created a learning environment that facilitated learning. The students in this study specifically mentioned that although the dog was a distraction, this distraction was a "positive distraction" that helped to calm them and relieve their stress. This finding was further supported from the results of the physiological part of the study, which showed that the average resting HR of the students was significantly lower when the dog was there, then when he was absent. Any state of relaxation is associated with a high level of parasympathetic stimulation and a reduction in the resting HR (Toscani et al., 1996; Verrier et al., 1998). It follows that the more relaxed a person is, the lower is the HR. Therefore, a possible explanation why the average minimum HR of the students was significantly lower when the dog was present than when the dog was absent, could be attributed to the students being more relaxed in class when the dog was there.

\section{General discussion}

Collectively, the findings from this study support previous research. Several studies on human-animal interactions, have produced the same or similar results as the current study. For example, Gocheva, Hund-Georgiadis, and Hediger (2017) investigated the immediate effects of AAT on the concentration and attention span of brain-injured patients during rehabilitation therapy. Findings 
from their study revealed that although the participants' attention span did not differ when the animal was present and when it was absent, patients were more concentrated and alert during AAT sessions when the animal was there when compared with control conditions. Likewise, in a pre and post-test study by Prothmann, Bienert, and Ettrich (2006) it was found that children and adolescents in a psychiatric facility rated themselves as being more attentive, more able to concentrate and being less distracted to the rehabilitation program after interacting with a dog for $30 \mathrm{~min}$. Prothmann et al. (2006) concluded that interaction with a dog was mentally and emotionally beneficial for the children and adolescents attending this rehabilitation program.

Whilst the above studies were focused on patients, other studies were found that focused specifically on students and how AAT can induce relaxation and increase human attention and concentration. In a qualitative study which was conducted by one of the authors of this paper and which involved the same dog, the same nursing program, yet a different cohort of nursing students, Griscti (2019) reported the presence of the dog during class time, reduced stress and created a positive learning environment for students. Although this study was qualitative in nature and methodologically different, the fact that the participants, site and dog were the same as this study, adds strength to results in the current study.

Similar findings were also reported in a study by Chesika and Derting (2015) who conducted two studies to explore the effects of dog therapy on the psychological and physiological stress levels of first-year female undergraduates. In the first study 27 , first-year college women were recruited and their blood pressure (BP), HR (HR), and psychological stress and arousal level were measured after interacting with therapy dogs. In the second study, the Chitika and Dertiong conducted an experimental study with 61 first-year female students (34 experimental and 28 control) to find out if interaction with a dog made a difference on the salivary cortisol level, psychological stress and arousal level for a dog-therapy group and a control group. Results showed that although there were no significant differences on diastolic BP, HR, or salivary cortisol levels between those the students were exposed to a therapy dog or those who were not, however, there was a significant decrease in psychological stress and increase in psychological arousal when students interacted with therapy dogs in both studies.

More recently, Banks et al. (2018) conducted a pre-post study to explore the impact of a brief human-canine interaction on college students using subjective measures of sustained attention, mind wandering, perceived stress, cognitive test anxiety, and state anxiety. These researchers also found that although interaction with the therapy dogs did not alter cognitive functions in the students, it did reduce their stress and anxiety during exam time.

\section{Conclusion}

In this study we explored in the introduction of a dog during the class time had an impact on the students' stress level and ability to pay attention in class. Similarly, other studies we found that although the presence of the dog had no impact on the attention span of the students, however, AAT was found to reduce stress in students and to create a positive learning environment. Based on these findings, we reject the hypothesis that AAT has a positive impact on the attention span of students in the class, while we accept the premise that AAT can reduce stress levels in students.

Overall, this study adds to the current literature on the therapeutic effect of pet therapy on mental health and education of undergraduate students. Implications from this study may help to promote universities as a pet-friendly environment, that are vested in reducing stress in students and that facilitate learning in a humanistic way.

The main strength of this research lies in the design of the study. Using the same subjects for experimental and control group increased the level of control in this research and made it easier to detect if there were any differences in findings were due to interaction with the dog or not. This reduced the error variance due to individual differences for every single participant was subjected to the treatment and to the control group. Another strength of this study was that we used repeated measures of HR when the dog was present and when he was absent. With the use of repeated measures, we were able to measure the effect of dog therapy over a specific time period. The repeated measures allow for more statistical power since they controlled for factors that may cause variability in the subjects.

Notwithstanding this study has its limitations. The study is limited to the use of a particular dog of a certain breed, who was calm temperament and who was well behaved in class. It is not known if other dogs and breed would have elicited a similar response. The fact that one of the researchers who conducted the study was also the same professor who was teaching the course at the time and the owner of the dog, may also have led to a social desirability effect when students were asked to share their experiences about having the dog in class. The professor tried to limit this impact by going out of the room when the students filled in the questionnaire and by asking the students not to write their names and to keep them anonymous. Finally, the execution of this study was limited by funding and resources. While the physiological tools used for this study were reliable and valid, more sophisticated tools exist that can measure more precisely stress in students, and their attention span during class time. It is recommended that if this study is replicated and if funds are available, physiological measures are monitored using HR variability tools which are better predictors of the impact of cognitive processes on physiological variables.

\section{Funding}

Cape Breton University RP Spring 2017 grant \#8032

The author(s) declare that they have no conflict of interests 


\section{Declaration of Competing Interest}

The author(s) declare that they have no conflict of interests

\section{Acknowledgements}

The authors would like to thank all the student nurses who participated in this study. This study would have not been possible without their willingness to participate.

\section{References}

Adamle, K. N., Riley, T. A., \& Carlson, T. (2009). Evaluating college student interest in pet therapy. Journal of American College Health, 57, $545-548$. Anderson, J. R. (2004). Cognitive psychology and its implications (6th Edition). Worth Publishers 519.

Banks, J. B., McCoy, C., \& Trzcinski, C. (2018). Examining the impact of a brief human-canine interaction on stress and attention. Human-Animal Interaction. Accessed 5 June 2019 https://www.apa-hai.org/human-animal-interaction/haib/examining-the-impact-of-a-brief-human-canine-interaction-on-stress-and-attention/.

Barker, S. B., Barker, R. T., McCain, N. L., \& Schubert, C. M. (2016). A randomized cross-over exploratory study of the effect of visiting therapy dogs on college student stress before final exams. Anthrozoös, 29(1), 35-46. https://doi.org/10.1080/08927936.2015.1069988.

Bayram, N., \& Bilgel, N. (2008). The prevalence and socio-demographic correlations of depression, anxiety and stress among a group of university students. Social Psychiatry and Psychiatric Epidemiology, 43, 667-672.

Beatty, J. (1989). Neurophysiology of sustained. Attention.VIgilance and performance in automatized Systems/Vigilance et performance de l'Homme dans les systèmes automatisés. 3-12.

American College Health Association (2016). Canadian reference group, executive summary, ACHA/NCHA II. https://www.acha.org/documents/ncha/NCHA-II \%20SPRING\%202016\%20CANADIAN\%20REFERENCE\%20GROUP\%20EXECUTIVE\%20SUMMARY.pdf.

Chesika, C., \& Derting, T. (2015). Effects of pet therapy on the psychological and physiological stress levels of first-year female undergraduates. North American Journal of Psychology, 17, 575-590.

Domantay, J. A. A. (2014). Health-related quality of life of future physicians at a medical school in the Philippines: A cross-sectional study. SAGE Open, 4(3) 2014 [2158244014545459-].

Dwyer, A., \& Cummings, A. (2001). Stress, self-efficacy, social support, and coping strategies in university students. Canadian Journal of Counselling, 35, $208-220$.

Elias, H., Ping, W. S., \& Abdullah, M. C. (2011). Stress and academic achievement among undergraduate students in Universiti Putra Malaysia.PRocedia. Social and Behavioral Sciences, 29, 646-655.

Furr, S. R., Westefeld, J. S., McConnell, G. N., \& Jenkins, J. M. (2001). Suicide and depression among college students: A decade later. Professional Psychology, Research and Practice, 32, 97-100.

Gocheva, V., Hund-Georgiadis, M., \& Hediger, K. (2017). Effects of animal-assisted therapy on concentration and attention span in patients with acquired brain injury: A randomized controlled trial. Neuropsychology, 32(1), 54-64. https://doi.org/10.1037/neu0000398.

Garg, K., Agarwal, M., \& Dalal, P. K. (2017). Stress among medical students: A cross-sectional study from a North Indian Medical University. Indian Journal of Psychiatry, 59(4), 502-504. https://doi.org/10.4103/psychiatry.IndianJPsychiatry_239_17.

Griscti, O. (2019). The therapeutic impact of dog therapy in undergraduate nursing students. Unpublished study.

Huss, R. J. (2012). Canines on campus: Companion animals at postsecondary educational institutions. Law Faculty Presentations and Publications, ValpoScholar, 44, $417-478$.

Kertes, D. A., Liu, J., Hall, N. J., Hadad, N. A., Wynne, C., \& Bhatt, S. S. (2017). Effect of pet dogs on children's perceived stress and cortisol stress response. Social Development, 26(2), 382-401. https://doi.org/10.1111/sode.12203.

Nagasawa, M., Mitsui, S., En, S., Ohtani, N., Ohta, M., Sakuma, Y., ... Kikusui, T. (2015). Oxytocin-gaze positive loop and the coevolution of human-dog bonds. Science, $348,333-336$.

Odendaal, J. S. J., \& Meintjes, R. A. (2003). Neurophysiological correlates of affiliative behaviour between humans and dogs. The Veterinary Journal, 165, 296-301. https://doi.org/10.1016/S1090-0233(02)00237-X.

Okena, B. S., Salinskya, M. C., \& Elsasa, S. M. (2006). Vigilance, alertness, or sustained attention: Physiological basis and measurement. Clinical Neurophysiology: Official Journal of the International Federation of Clinical Neurophysiology, 117(9), 1885-1901. https://doi.org/10.1016/j.clinph.2006.01.017 28.

Oxford dictionary (2019). Oxford dictionary online. https://www.lexico.com/en.

Pagnin, D., \& DeQueiroz, V. (2015). Influence of burnout and sleep difficulties on the quality of life among medical students. Springerplus, 4(1), 676.

Park, G., \& Thayer, J. F. (2014). From the heart to the mind: Cardiac vagal tone modulates top-down and bottom-up visual perception and attention to emotional stimuli. Frontiers in Psychology, 5, 278.

Pugliese, A., Famulari, L., \& Britti, D. (2010). Pet therapy and geriatrics: A social-sanitary connection. BMC Geriatrics(Suppl. 1), https://doi.org/10.1186/1471-231810-S1-L25 L25.

Prothmann, A., Bienert, M., \& Ettrich, C. (2006). Dogs in child psychotherapy: Effects on state of mind. Anthrozoös, 19, $265-277$.

Ribeiron, J. S., Pereira, R., Freire, I. V., De Oliveira, B. G., Casotti, C. A., \& Boery, N. A. (2018). Stress and quality of life among university students: A systematic literature review. Health Professions Education, 4, 70-77.

Ryan, M. L., Shochet, I. M., \& Stallman, H. M. (2010). Universal online resilience interventions might engage psychologically distressed university students who are unlikely to seek formal help. Advances in Mental Health, 9(1), 73-83.

Safree, Yasin, \& Dzulkifli (2010). The relationship between social support and academic achievement among students. International Journal of Business and Social Sciences, 1(3), 110-116.

Taylor, D. J., Bramoweth, A. D., Grieser, E. A., Tatum, J. I., \& Roane, B. M. (2013). Epidemiology of insomnia in college students: Relationship with mental health, quality of life, and substance use difficulties. The Behavior Therapist, 44(3), 339-348.

Thayer, J. F., \& Lane, R. D. (2000). A model of neurovisceral integration in emotion regulation and dysregulation. J. Affect.Disord. 61, 201-216. https://doi.org/10. 1016/S01650327(00)00338-4.

Toscani, L., Gangemi, P. F., Parigi, A., Silipo, R., Ragghianti, P., Sirabella, E., \& Zaccara, G. (1996). Human HR variability and sleep stages. Italian Journal of Neurological Sciences, 17, 437-439 doi:10.1007/BF01997720, pmid:8978452.

Vaez, M., \& Laflamme, L. (2008). Experienced stress, psychological symptoms, self-rated health and academic achievement: A longitudinal study of Swedish university students. Social Behavior and Personality, 36(2), 183-196. https://doi.org/10.2224/sbp.2008.36.2.183.

Vago, D. R., \& Zeidan, F. (2016). The brain on silent: Mind wandering, mindful awareness, and states of mental tranquility. Annals of the New York Academy of Sciences, 1373(1), 96-113. https://doi.org/10.1111/nyas.1317.

Verrier, R. L., Lau, T. R., Wallooppillai, U., Quattrochi, J., Nearing, B. D., Moreno, R., \& Hobson, J. A. (1998). Primary vagally mediated decelerations in HR during tonic rapid eye movement sleep in cats. The American Journal of Physiology, 274, R1136-R1141 pmid:9575980.

Wang, X., Pinol, R. A., Byrne, P., \& Mendelowitz, D. (2014). Optogenetic stimulation of locus ceruleus neurons augments inhibitory transmission to parasympathetic cardiac vagal neurons via activation of brainstem 1 and 1 receptors. Journal of Neuroscience, 34(18), 6182. https://doi.org/10.1523/JNEUROSCI.5093-13.2014.

Wood, E., Ohlsen, S., Thompson, J., Hulin, J., \& Knowles, L. (2018). The feasibility of brief dog-assisted therapy on university students stress levels: The PAwS study. Journal of Mental Health, 27(3), 263-268.

West, C. P., Shanafelt, T. D., \& Kolars, J. C. (2011). Quality of life, burnout, educational debt, and medical knowledge among internal medicine residents. Journal of the American Medical Association, 306(9), 952-960. 